\title{
VICTIMIZACIÓN Y DESPLAZAMIENTO FORZADO DE MUJERES EN EL CONFLICTO ARMADO COLOMBIANO
}

\author{
Edwin Diego Salcedo Ávila ${ }^{1}$ e Eduardo Paes-Machado ${ }^{1}$ \\ ${ }^{1}$ Universidade Federal da Bahia, Salvador, BA, Brasil
}

La violencia colectiva en Colombia tiene efectos graves sobre la vida, el cuerpo y la mente de la población civil, pero, sobre todo, afecta a los segmentos más vulnerables como las mujeres. Mujeres que en su mayoría son de origen campesino han perdido el ejercicio de todos sus derechos. Los eventos violentos victimizan y obligan a muchas mujeres a salir de sus regiones de origen, como única forma de conservar la vida en lo que se ha denominado desplazamiento forzado.

Para discutir esta victimización enfatizamos el concepto de género como el campo primario, persistente y recurrente en el que, de manera compleja, se articula el poder. Por lo tanto, defendemos que el género se implica en la percepción, en la construcción y en la legitimación de los ejercicios de poder (Cifuentes 2009). En esa línea, también destacamos el significado de los roles de género en términos de las expectativas, tareas y actividades asociadas con la condición cambiante tanto de hombres como de mujeres. En el caso de las mujeres, no se puede perder de vista, por ejemplo, las expectativas histórico-culturales y sociales focalizadas en ellas como cuidadoras y protectoras de la familia y en especial de la prole. De esta forma, coincidimos en que la inequidad y los desequilibrios de poder entre los géneros se exacerban en contextos de conflicto armado (Malakunas 2001).

Ahora bien, son pocos los estudios que han abordado de modo articulado los varios tipos de victimización de las mujeres dentro del conflicto armado colombiano. Entre estos trabajos, Osorio (2008) analizó los actos violentos sufridos por la población femenina, como agresiones sexuales, restricciones de su libertad y ruptura de sus redes familiares, afectivas y sociales. Aquí buscamos ampliar este análisis incorporando las victimizaciones representadas por las pérdidas materiales y las pérdidas efectivas y potenciales de los otros significativos o más allegados. ¿ Qué significado tienen estos fenómenos para las mujeres en las zonas de conflicto armado? ¿Cuáles son las reacciones y respuestas de ellas a la violencia colectiva? Argumentamos que 
esas victimizaciones las afectan como mujeres y como madres, cuidadoras y protectoras de sus familias y, en especial, de su prole. Además, proponemos que, si bien estas mujeres fueron víctimas de los grupos armados y las dinámicas destructivas de la guerra, también se constituyeron como agentes que lucharon por sobrevivir y enfrentar la violencia en lo cotidiano y a si mismo buscaron proteger a sus seres queridos.

\section{El conflicto armado colombiano}

El conflicto armado colombiano es una clase de conflicto complejo y de difícil definición. Se han realizado diferentes análisis y estudios para comprender la naturaleza de este conflicto que es bien singular, de baja intensidad, pero de larga duración y con dinámicas particulares que con el tiempo y a lo largo de la historia, ha adoptado diferentes modalidades. Los estudios e investigaciones acerca del conflicto que vive Colombia han pasado por diferentes teorías criminológicas donde se abordan elementos claves como los motivos, medios y oportunidades de los actos criminales (Medina 2009), hasta tomar postura entre las teorías que se fundamentan en lecturas de doctrina revolucionaria- aquellas que dicen respecto a modelos insurreccionales, supuestos, variantes y tácticas de los grupos armados insurgentes, así como, las propias estrategias y tácticas de la lucha contrainsurgente (Kurtenbach 2005). El conflicto colombiano ha sido bastante heterogéneo tanto a lo largo del tiempo como en la extensión del territorio. En él han participado diferentes grupos, con diferentes ideologías y tendencias políticas, las víctimas son muchas, pertenecientes a grupos políticos, étnicos y de organizaciones civiles igualmente diversos. Por otro lado, los repertorios de la violencia, sus lógicas y características han sido diferentes dependiendo de los contextos y las diversas formas que adopta la confrontación armada. El recurso a la violencia como forma de solucionar conflictos o establecer estrategias políticas, aparece en algunos sectores específicos o grupos focalizados, como los grupos guerrilleros, paramilitares, bandoleros, políticos, bandas criminales o narcotraficantes (Carbó 2006). Esos grupos recurren a la violencia para satisfacer sus intereses ya sean económicos, políticos o sociales. En otras ocasiones, dada la falta de garantías por parte de las instituciones, la inequidad o la falta de justicia, algunos grupos o personas recurren a la violencia para reclamar derechos o solucionar problemas particulares. La violencia, entonces, viene como recurso para intentar legitimar políticas y como estrategia de reivindicación social, política o económica de algunas minorías y sectores particulares del 
país. Estas estrategias y recursos están relacionados con la fragilidad del Estado y la crisis de las instituciones y se manifiestan en dos vertientes. Por un lado, las elites civiles han dominado la gestión económica y política, ejerciendo el poder sobre las clases populares sin que el Estado tenga un control o quede limitado para ejercer sus verdaderas funciones (Rangel 1998). Por otro lado, es en esta falta de garantías por parte del Estado y el déficit en el ejercicio del control y poder estatal, que los grupos armados, guerrillas y paramilitares hacen uso de la fuerza y desestabilizan las instituciones (Kurtenbach 2005).El conflicto armado no se agota con las actuales negociaciones y la desmovilización de las guerrillas de las FARC. Aún persiste la acción de otras insurgencias como el ELN, las disidencias de las mismas FARC y las llamadas bandas criminales, reducto de los grupos paramilitares, reacomodo interno entre estructuras altamente fragmentadas, volátiles y cambiantes, fuertemente permeadas por el narcotráfico, más pragmáticas en su accionar criminal y más desafiantes frente al Estado (Centro de Memoria Histórica 2013). De cualquier forma, los costos materiales y humanos del conflicto han sido elevados. Respecto a los costos financieros, los gobiernos nacionales han gastado entre 1978 y 2016, 332,95 billones de pesos (Prada 2016), lo que equivale a 110 mil millones de dólares. El conflicto ha causado la muerte de aproximadamente 262 mil personas entre 1958 y 2018 (Centro de Memoria Histórica 2018). En cuanto al desplazamiento forzado, entre 1997 y 2017 han sido registradas oficialmente 7.4 millones de personas desplazadas con un impacto desproporcionado en la población afrocolombiana y las comunidades indígenas a pesar del acuerdo firmado con las guerrillas de las FARC (ACNUR 2017). Con respecto a la población femenina, las mujeres representan el 49.73\% del total de víctimas que deja el conflicto armado hasta hoy. (Unidad de Victimas, 2018). Especificando que 3.780.677 de ellas fueron víctimas de desplazamiento; 458.781, víctimas de feminicidios; 191.784, de amenazas; 77.100, de desaparición forzada; 47.627, de perdida de bienes muebles o inmuebles; 40.231 son víctimas de actos terroristas, atentados, combates y hostigamientos; y, 17.350 víctimas por violencia sexual. (Unidad de Victimas, 2018).

\section{Metodología}

Para el planeamiento y la selección de la muestra de esta investigación se tuvo en cuenta una actividad previa realizada con familias campesinas víctimas del conflicto armado en la ciudad de Bogotá y a través de una ONG, La Fundación de Atención al Migrante (FAMIG). Este trabajo con- 
sistió en una caracterización de la población desplazada que llegaba a la capital colombiana huyendo de las acciones de los grupos armados y que se ubicaban en los barrios marginales del sur de Bogotá. Dicha actividad se realizó en 2009 y 2010 con 125 familias desplazadas por la violencia colectiva y obtuvo notas de campo y registros de entrevistas abiertas. Con esta primera inmersión en el campo se comenzó la planeación, la definición de los objetivos y la selección de los sujetos de la investigación. En este caso, se decidió realizar una serie de entrevistas con mujeres desplazadas que también vivían en Bogotá y que habían pasado por eventos de violencia en sus regiones de origen por cuenta del conflicto armado. Fueron realizadas 19 entrevistas a mujeres que pertenecían a un programa de ayuda en el año 2013. Estas entrevistas fueron abiertas y se realizaron en las instalaciones de la Fundación de Atención al Migrante (FAMIG). Las mujeres en su mayoría eran campesinas y otras se dedicaban al comercio informal en sus lugares de origen. Ellas tenían más o menos 5 años de haber llegado a la ciudad, y en ese momento estaban en proceso de generar nuevos proyectos de vida con la ayuda de dicha ONG. La edad de estas mujeres estaba entre los 30 y 60 años de edad. En un segundo momento se realizaron 29 entrevistas semiestructuradas que contenían tres ejes: el primero buscaba indagar sobre el origen de las mujeres, sus vidas en los territorios o regiones y la forma como sufrieron los eventos violentos; el segundo, hacía referencia a las formas de salida, el éxodo y las rutas de migración; en la tercera parte o eje, se buscaba preguntar sobre las condiciones de llegada a Bogotá, los nuevos asentamientos y luchas por la sobrevivencia en la ciudad. Estas mujeres en su mayoría eran campesinas, otras eran comerciantes y algunas tenían formación técnica. Estaban en una franja etaria de entre 18 y 65 años de edad. Se incluyeron mujeres mestizas, indígenas y negras reconocidas por los registros oficiales como víctimas de los grupos armados. La entrevista semiestructurada se caracteriza por el hecho de que el entrevistador tiene un guion que recoge los temas que va a tratar a lo largo de la ejecución (Grinnell \& Unrau 2007) pero que puede ser flexible. Este aspecto es importante porque el tema a tratar con estas mujeres es complejo y no sería conveniente tener un protocolo de preguntas ya preconcebidas. En el ámbito de las conversaciones sobre violencia, eventos traumáticos o episodios de victimización se deben efectuar preguntas oportunas y hacerlo en términos convenientes. Dado el caso, se deben introducir comentarios que ayuden a mantener la calma y reestablecer el diálogo. Se debe establecer un estilo propio y personal de conversación teniendo en cuenta la complejidad de los temas a tratar (información confidencial, problemas de seguridad por amenazas) y el conocimiento sobre el conflicto armado en particular (Salcedo 
2015). Teniendo en cuenta la dificultad para hablar sobre violencia sexual con algunas de las mujeres, fue necesario usar como método de recolección, lo fundamentado en datos secundarios (Hernandez 2010). Así se tuvo acceso a relatos escritos por ellas en los talleres de memoria y duelo realizados por la psicóloga de la fundación. Dichos talleres consistían en expresar de forma escrita o mediante dibujos cómo estas mujeres habían sido víctimas de violencia sexual. El acercamiento a estas mujeres se realizó mediante conversaciones informales en una primera instancia. Luego, a través de la participación en actividades dentro de la fundación para una familiarización con el ambiente y observación no participante. Así como mediante snowball sampling (Biernacki \& Waldorf 1981), en el cual la muestra fue definida por medio de la indicación de colaboradores que se dispusieron a presentar a otras personas que podrían participar en la investigación. En un primer momento se realizaron las transcripciones de las 19 entrevistas realizadas de manera exploratoria. Se ubicaron categorías de análisis para diseñar la segunda etapa de la investigación. En la segunda etapa fue necesario un proceso de familiarización con los datos para establecer códigos y categorías para luego comenzar a generar definiciones, construir mapas conceptuales y establecer significados en las narrativas teniendo en cuenta los tipos de victimización. El tratamiento de los datos en esta fase se desarrolló por el empleo del método de comparación constante (Carriço \& Mattos 2012) luego de la transcripción de las 29 entrevistas. Fue a través de la identificación de las formas de victimización susceptibles de codificación que el análisis se desenvolvió y tuvo tres fases: codificación abierta, codificación axial y codificación teórica según el esquema de la teoría fundamentada en los datos (Charmaz 2006).

\section{Ambiente militarizado}

El ambiente en las regiones del país donde operan las organizaciones armadas se asemeja al estado de excepción (Agamben 1998) que sustrae a los sujetos del amparo de las leyes, los somete a las reglas de los detentores de las armas y los priva de la libertad e incluso de la vida. Esto implica, entre otros aspectos graves, un control y normativización de la vida cotidiana, la invasión de lo privado, la censura a la participación social y la diseminación del miedo crónico. Se ejerce un poder físico y simbólico que se despliega de manera rutinaria dentro de la vida cotidiana y no necesariamente se manifiesta como fuerza física: invadiendo los dominios de la sociedad considerada civil, promoviendo relaciones de dominación y subordinación 
y permeando costumbres y ámbitos familiares. En todos esos dominios se vulnera a la población civil y en particular a las mujeres que quedan en el fuego cruzado y tienen que lidiar con los intereses de las organizaciones armadas (Bennett, Bexley \& Warnock 1995; Estrada, Ibarra \& Sarmiento 2007): "La guerrilla lo involucraba a uno en todo lo que ellos hacían...una vez a mi marido se lo llevaron para que ayudara a descargar un camión que ellos se habían robado" (Lucely, 33 años).En un ambiente de militarismo, lo único legítimo es aquello que proviene del héroe masculino y dominador, aquél que enfrenta al enemigo (Pino 2004). Pero lo militar no es sólo el conjunto de actividades protagonizadas por los militares o las organizaciones ilegales armadas. A menudo, los civiles prestan apoyo o actúan con este enfoque militarista (Enloe 1995), por ejemplo, cuando se ejerce presión sobre familiares para ingresar a los grupos armados: "Yo sé cómo es que funciona todo allá en la guerrilla, conocía mucha gente que estaban ahí como milicianos, yo tenía primos en la guerrilla, llegaban a la casa para decirnos que nos fuéramos para allá, para el grupo" (Yomara, 40 años). Para los grupos armados, la población civil se divide entre ser aliada o ser una prolongación del enemigo (Centro de Memoria Histórica 2013). De igual forma, ellos saben cómo manipular los juegos de discurso y el uso perverso de los miedos (Cifuentes 2009) para estimular lealtades y mantener la población como servidora o adepta a las organizaciones armadas (Waldmann 1997; Estrada, Ibarra \& Sarmiento 2007). Las amenazas contra la población son tanto una forma de intimidación, como una conminación a hacer o dejar de hacer, como en el caso de mujeres que se rehúsan a obedecer el mandato de terror, o como paso previo para consumar otras violaciones (Ruta Pacífica de las Mujeres 2013). Cualquiera que no entre en el marco ideológico o político de la organización armada es amenazado o señalado. Fue lo que pasó con algunas activistas de organizaciones de derechos humanos que investigaban delitos cometidos por las fuerzas del gobierno:

Yo siempre he trabajado con derechos humanos y estaba vinculada con una ONG [organización no gubernamental] haciendo un trabajo de campo sobre crímenes de Estado; éramos cinco mujeres, nosotras teníamos un grupo que iba a las zonas donde ocurrían las cosas y a raíz de eso comenzaron las amenazas, dijeron que nosotras ayudábamos a la guerrilla (Nancy, 46 años).

Del mismo modo, otras formas de participación social de las mujeres las llevó a ser censuradas y perseguidas, pues esto cuestionaba los lazos de subordinación (Sánchez 2008), las restricciones tradicionales a la participación femenina en la esfera pública y la pretensión de los grupos armados en el monopolio del poder: 
Pues allá yo hacía mucho trabajo social, trabajaba con la alcaldía, yo pedía ayudas a las ONG para la gente que lo necesitaba, íbamos a los campos para colaborarle a la gente... creen que uno tiene nexos con la política y entonces empiezan a amenazarlo a uno, me decían que por qué yo pedía ayudas, que para qué hacía eso, pues yo quería hacerlo, porque me gustaba ayudar a la gente del campo, pero no para hacer política... es que una mujer como yo, insignificante, tal vez a esa gente [guerrilleros] les causó como recelo, envidia, que yo pudiera hacer eso y entonces me empezaron a amenazar, dijeron que iban a matar a mi familia (Edith, 49 años)

Sin embargo, la sanción más grave tocó directamente a las personas que colaboraron con el adversario y a sus parientes:

En Currillo, Caquetá, mataron muchas personas, yo me di cuenta de eso, cuando salimos de allá fue porque uno colaboró con esa gente, por la manera de pensar, ¿entiende?...a mi marido también se lo llevaron, fue por eso; allá nadie podía hacer nada, no se podía ni salir, le decían a uno a qué hora se debía acostar y todo era así (Martha Lucia, 37 años)

A pesar de que las parientes de los colaboradores no fueran asesinadas, ellas pasaron a vivir bajo un rígido régimen de control y vigilancia impuesto por el grupo armado. Se evidencia así, una delimitación de espacios en donde el orden jurídico normal (Agamben 1998) es reemplazado por el ethos militar fundado en el uso de la fuerza máxima, ya sea que provenga de fuerzas del estado (Brodeur 2004) o de grupos ilegales. Bajo dichas presiones, el miedo se convirtió en la emoción más constante y generalizada. Una expresión de esto fue la zozobra, la desconfianza y la hipervigilancia que acompañó la llegada de contingentes armados a los corregimientos y a los hogares. En ese ir y venir de los grupos armados, las mujeres quedaron en estado de perplejidad, de confusión, sin saber quién era el victimario; de lo único que tuvieron certeza fue de la constante amenaza. En otros términos, el miedo crónico (Lira 1991) dejó de ser una reacción específica a situaciones concretas y se transformó en un estado permanente.

\section{Tipos de victimización}

El conflicto bélico colombiano, a ejemplo de muchos otros, debe ser visto tanto como un proceso de estructuración (Giddens 1984; Walklate 2003) como de promoción y materialización de oportunidades de victimización efectiva, potencial, recurrente y masiva de la población civil y más enfáticamente 
de las mujeres, que han estado en clara posición de desventaja frente a los hombres (Osorio 2008; Cockburn 2005; Cifuentes 2009). A pesar de que la separación de los diferentes tipos de violencia sufridos sea complicada por el hecho de que son en extremo desestructurantes por la imbricación de sus formas y sus efectos, utilizamos las nociones de victimización directa e indirecta para ordenar ese flujo de experiencias. La victimización puede ser directa cuando involucra los hechos delictivos o violentos practicados contra las propias mujeres; o indirecta, cuando estos hechos fueron direccionados contra otros significativos o más allegados, pero que terminaron afectando, a veces de modo más severo, a las mujeres. Así, en la victimización directa incluimos las dimensiones material y sexual. Y la victimización indirecta de las mujeres comprende los asesinatos y desapariciones de parientes o personas más allegadas. Aunque la victimización psicológica haya sido un componente fundamental de esas experiencias, preferimos tratarla en conjunto con las otras victimizaciones.

\section{Pérdidas materiales}

La victimización directa y material afectó a mujeres de zonas rurales y urbanas en las regiones de conflicto. Tal victimización fue provocada por la destrucción, la ocupación y apropiación de los bienes, la explotación de la fuerza laboral y la pérdida de puestos de trabajo. La violencia impactó mayoritariamente a las campesinas que derivaban la mayor parte de sus ingresos de actividades agropecuarias. Estos bienes hacían parte de la economía familiar y no en todos los casos eran propiedad de las mujeres. Sin embargo, significaban una fuente esencial de trabajo e ingresos para el sustento del grupo familiar: "Yo perdí todo, como le conté: las gallinas, el cultivo de pescado, todo eso quedó allá para la guerrilla...yo tenía ese negocio con mi marido y nosotros surtíamos los restaurantes del pueblo, de eso vivíamos" (Mary, 56 años). En primera instancia, los combates entre grupos armados afectan el hábitat y los activos productivos (Osorio 2008) de las familias campesinas. La población queda en medio del fuego cruzado sin oportunidad de proteger sus pertenencias y con la resignación de vivir experiencias repetidas de destrucción por ataques o bombardeos: "Eso cada rato habían combates en el pueblo, uno ya sabía cuándo sonaban los tiros, la casa quedaba cerca a la estación de policía y pues ahí nos rompían los vidrios, las puertas... una vez se nos cayó el techo encima" (Amparo, 45 años). La casa significa una pérdida importante para estas mujeres pues está ligada a los afectos, al cuidado de los hijos, a todo aquello que implica el hogar para ellas. A su vez, la ocupación de bienes por parte de los grupos armados era frecuente, ya sea en la modalidad de allanamiento o como una forma de hacer requisas 
o robos. En algunas ocasiones se apropiaban de las fincas y casas para vivir, haciendo uso de bienes y pertenencias personales: "Cuando llegaban a la casa [paramilitares] cogían de todo, entraban al baño, se llevaban el jabón, hasta mis cosas personales...en la cocina no dejaban ni las ollas, cogían de todo" (Teyla, 35 años). La apropiación de pertenencias sin consentimiento es una violación cometida por los diferentes grupos, incluso por las fuerzas del Estado. Corriente también fue el robo de animales con la justificación de aportar a la lucha armada guerrillera o como una forma de venganza y desprecio para con las víctimas (Ruta Pacífica de las Mujeres 2013). Algunas mujeres también fueron víctimas de pillaje cuando se negaban a pagar extorsiones o impedían el reclutamiento de sus hijos: "Yo tenía un negocio de ropa y como yo no quise que se llevaran a mi hija, entonces siempre llegaban [paramilitares] y cogían camisetas, pantalones, cosas así...después yo fui en pérdidas y me toco salir del pueblo, dejar el negocio" (Carmen, 42 años). Las pérdidas generadas por los hurtos, robos y saqueos obligan a esta mujer a abandonar su región. ${ }^{1}$ A la vez, estos despojos generan pobreza y pérdida de la autonomía económica lograda con tanto esfuerzo por ellas (Meertens 2006; Ruta Pacífica de las Mujeres 2013). Asociado con estos actos, a estas mujeres se les asignan trabajos civiles o militares ligados al conflicto armado. Ellas tienen que trabajar en dobles jornadas, por un lado, asistiendo a sus familias y por el otro, colaborando en las tareas que exigían los grupos armados como hospedarlos en sus casas, cocinar y comprar artículos diversos en los pueblos o ciudades vecinas. Estas mujeres tienen que atender diferentes demandas por parte de los grupos armados, demandas contradictorias que afectan las diferentes formas de percibir sus identidades (Stasiulis 1999) y que en muchos casos asumen un carácter de explotación y esclavización. Con estas pérdidas vinieron las rupturas de la cotidianidad, de lo que era la esencia de la vida y la existencia misma. Aquí es importante destacar que el espíritu campesino se define por la atadura a su campo y a sus animales, y no puede resistir mucho tiempo a esa pérdida. El campesino está poseído por su propiedad más de lo que él la posee (Bourdieu \& Abdelmalek 1964). Tales pérdidas están articuladas con los significados que dan las mujeres a dichos objetos; es decir, para ellas el trabajo de toda una vida tiene un simbolismo representado en su autorreconocimiento. La estima y la valoración del sí mismo se van con el objeto perdido, aparece la nostalgia como una herida narcisista ocasionada por dichas pérdidas (Uriarte 1998). La tristeza y la melancolía son características en las mujeres que poseían bienes propios, tristeza asociada al vacío, al pesimismo y la desesperanza. Entre otras cosas, las pérdidas materiales suponen para estas mujeres un declive social y una ruptura de los proyectos de vida, generando astenia, 
inhibición, sentimientos de inferioridad (Uriarte 1998) y una consecuente pérdida de la dignidad (Ruta Pacífica de las Mujeres 2013). Para las mujeres que lo perdieron todo no quedó sino la incertidumbre y el desconcierto. Para esta situación no es posible hallar explicación o, por lo menos, no se halla la razón por la cual se tuvo que renunciar a su mundo y a todo lo que se poseía. En el caso de mujeres campesinas es un cambio radical en la organización de la familia y la pérdida del papel fundamental que ellas ocupaban en el sustento de sus hogares. También la sobrevivencia de aquellas mujeres dedicadas a actividades del comercio informal o la prestación de servicios se vieron afectadas por la inseguridad y la violencia: "Yo había colocado un puesto de comidas y vendía almuerzos, ya cuando llegaron [los guerrilleros] me decían que me pagaban, pero no, eso ya no me sentía bien, me daba mucho miedo, con esa gente ahí metida" (Lucely, 33años). Así mismo, la presencia de los grupos armados en los espacios privados supuso una ruptura de las rutinas cotidianas y un riesgo constante (Lira 1991). Sin embargo, las pérdidas para las mujeres que trabajaban en el sector de servicios o el trabajo informal adquieren otro sentido. El arraigo no es tan marcado para ellas, por lo general eran solteras o poseían habilidades comerciales que les permitían moverse de un lugar a otro. La edad también influyó en la percepción de las pérdidas, dado que algunas mujeres eran jóvenes y no tenían propiedades, no tenían familias constituidas y poseían cierta autonomía para moverse o desempeñarse en cualquier empleo. Las pérdidas materiales para este grupo son quizá más fáciles de reponer, la permanencia del objeto no es tan duradera y su significado es diferente en la red simbólica o de valores: "Yo siento nostalgia por el pueblo, pues uno vivía allá y todo, pero eso de campesina no es conmigo, yo he sido muy independiente, muy libre" (Marisela, 27 años). Eso también se reflejó en su identidad y la forma como afrontaron la violencia, así como en la capacidad de encontrar nuevas oportunidades laborales y de sobrevivencia en los lugares de destino a donde se desplazaron: "Yo allá trabajaba en lo que saliera, en casas de familia, vendiendo comida, siempre así, nunca tuve trabajo estable y ahora aquí [Bogotá] me toca en lo mismo" (Rosana, 29 años). De cualquier forma, las mujeres son más flexibles, están mejor preparadas para afrontar las pérdidas materiales y asumir otras labores durante el desplazamiento forzado, diferente a lo que ocurre con los hombres más atados a la tierra (Meertens 2006).

\section{Violencia sexual}

En las zonas de conflicto armado la tensión y la normalización de la violencia permite la apropiación, utilización y abuso del cuerpo de las mujeres por los varones en guerra (Theidon 2006). Esta violencia que se 
constituye como una estrategia de guerra para desestabilizar a los sujetos y a las comunidades (El Jack 2002) ${ }^{2}$, asume la forma de acosos, explotación sexual, violaciones y torturas. La ocupación de los espacios privados por parte de los grupos armados llevaba consigo la constante amenaza para las mujeres en el hogar y las fincas: "como llegaban a la casa [paramilitares] tocaba atenderlos, y lo miraban a uno de arriba abajo...a veces me tocaban, se reían y hacían vulgaridades con las manos, yo me sentía muy incómoda" (Deisy, 29 años). Dichas invasiones eran acompañadas muchas veces por acosos a menores de edad": "Siempre que llegaban a la casa a cobrar la vacuna [extorsión] miraban a mi hija, ella es muy bonita, yo sentía que lo hacían con morbosidad" (Carmen, 36 años). Muchas veces la ausencia de los hombres en los hogares o la impotencia de ellos frente a la amenaza armada reducía la vigilancia y hacía que las mujeres fuesen más vulnerables frente a los ataques predatorios: "A uno le daba miedo porque decían que se metían a las fincas y violaban a las muchachas, uno vivía con ese temor, yo no podía dormir, a los hombres se los llevaban, uno no sabía qué pasaba con ellos, nosotras nos quedábamos solas" (María Dolores, 34 años). La violencia sexual se revela como un medio de exhibición del poder masculino y, de nuevo, como instauración del miedo. A su vez, en los espacios públicos, la libertad individual, la movilidad y la expresión corporal femenina son restringidas o utilizadas como justificación para acosos y violaciones:

Uno como es de tierra caliente pues se viste muy ligero, con escote y en short, no podíamos salir de noche, todo eso...pero entonces ellos [paramilitares] empezaban a molestar y decían que si nos vestíamos así éramos putas...entonces nos acosaban, nos decían que lo que buscábamos era que nos violaran. A varias muchachas las violaban por vestirse así (Deyanire, 35 años).

La opresión se extiende a la imposición de vínculos afectivos, a la obligación de convivir y a tener relaciones sexuales con hombres armados (Ruta Pacífica de las Mujeres 2013). En las zonas de conflicto algunas mujeres terminan estableciendo relaciones afectivas con miembros de grupos armados (Ruta Pacífica de las Mujeres 2013). A pesar del carácter impositivo de estos lazos, que pasa por el uso de la coacción, estos no dejan de involucrar una ambivalencia que se expresa en el desarrollo de sentimientos entre víctimas y victimarios. Dentro de las guerrillas, por ejemplo, menores de edad son reclutadas mediante falsas promesas y allí son víctimas de abusos que resultan en embarazos y abortos (Ruta Pacífica de las Mujeres 2013). Además de ser utilizadas con fines sexuales, estas mujeres también cumplen funciones de inteligencia e información. En esta misma línea, jefes de los paramilitares practicaban violencia sexual contra las mujeres y después de ser utilizadas 
por ellos eran entregadas a sus subordinados. Así mismo, jóvenes ingenuas que por falta de recursos o por encontrarse en desventaja social, buscaban nuevas oportunidades dentro de los grupos armados y fueron seducidas por hombres que invadían sus hogares o las abordaban en espacios públicos y al final fueron prostituidas e incluso asesinadas:

En el pueblo había un paramilitar, el jefe de esa gente, y cogía cualquier niña y se la llevaba, por las buenas o a las malas, andaba con ella unos días y luego se la entregaba a los que andaban con él...aunque también varias chicas les gustaba andar con esa gente, pero cuando se aburrían de ellas, las mataban, un día encontraron a una en un hueco, las violaban y las tiraban (Andrea, 20 años).

Las menores de edad también se veían involucradas en situaciones y a veces en relaciones en las que la desigualdad de poder superaba su capacidad de mantenerse a salvo de la relación con actores armados cuya intención principal era utilizarlas y abusar sexualmente de ellas (Ruta Pacífica de las Mujeres 2013). Se establece para estas mujeres una situación ambigua entre seducción y amenaza. La degradación del cuerpo femenino también se expresó en las violaciones cometidas por varios hombres al mismo tiempo. El cuerpo de mujeres acusadas de pertenecer al bando enemigo es utilizado como botín de guerra y campo de orgia o confraternización perversa: “donde yo vivía, seguido entraban los "paras" [paramilitares], buscando gente, ahí llegaron a mi casa y me cogieron cinco tipos y todos me violaron, yo no sabía qué hacer, ni podía gritar...tenían la cara tapada y me insultaban, decían que yo era guerrillera, que iban a matar a mi familia porque éramos guerrilleros" (Sandra, 35 años). A la par de la violencia sexual, muchas de esas víctimas sufrieron otros castigos físicos.

A mí me amarraron y me metieron a un carro [paramilitares], hablaban de los que habían matado, se reían y se burlaban. Comenzaron a decir que había gente que estaba metiéndose en lo que no les importaba, ellos decían: "son unas perras, unas zorras y los que se meten, pues se mueren", y me señalaron a mí. Me decían muchas vulgaridades, me tocaban... es un estado que nunca me imaginé, me sentía herida en mi ego. Luego me amarraron a un árbol y me dieron latigazos, me hicieron de todo...un comandante se acercó y me dijo: "eso le pasa por meterse en lo que no debe, por abrir la boca", yo capté que era por haber estado en la alcaldía y en la junta comunal del pueblo" (Solteny, 48 años).

Se evidencia como la coacción física y psicológica fue un preámbulo para las agresiones sexuales sufridas por esta mujer. Pero además se ejerce tortura sobre ella como represalia por mantener contacto con las autoridades locales, transgrediendo la división de los espacios privado/público (Oosterhoff, Mills 
\& Oosterom 2014; Estrada, Ibarra \& Sarmiento 2007) y desafiando el régimen patriarcal impuesto por los grupos armados. A su vez, más allá de la acción directa sobre esta mujer, lo que busca la violencia sexual es extender el terror y la amenaza sobre las mujeres que simbolizan la resistencia. En algunas ocasiones junto con la violación se realizaron torturas para desfigurar, dejar cicatrices visibles y denigrar el cuerpo: "me hacían muchas cosas, cogieron un palo y me lo soltaban en la espalda, en las piernas, me dejaron moradas las piernas, vuelta nada, molida...me dolía mucho y luego me violaron, eran como tres encapuchados" (Blanca, 32 años). Así mismo, las lesiones en genitales fue una práctica extendida por los grupos paramilitares. Otras prácticas comunes fueron las violaciones y torturas en plazas, parques o sitios públicos para que la población sirviese de espectadora (Centro de Memoria Histórica 2013). El cuerpo torturado se hace público como una forma de terror ejemplificante: "ellos [paramilitares] decían que las mujeres que se portaran mal serian castigadas, fregaban por todo...un día desnudaron a una muchacha en el parque, nos reunieron a todos... eso la manoseaban, le cogían las nalgas, hasta le pegaron, le gritaban cosas feas y la insultaban" (María, 51 años). En estas prácticas se pone en juego la imposición del terror, se deja ver cómo las víctimas son "construidas" o hechas por medio de la demolición del yo y la humillación psicológica (Manero \& Villamil 2007). Es a través del cuerpo de la mujer que se expresa la dominación, por eso se le marca, se abusa de él, ya sea para destruirlo o para afectar su identidad, o como retaliación indirecta a los varones enemigos (Pino 2004). Es una prueba confirmatoria de la reputación violenta del superior jerárquico (Almeida \& Paes-Machado 2013). Estas mujeres tuvieron que pasar por situaciones de humillación, vejaciones personales y atentados contra su autoimagen como en los casos de los embarazos que resultaron de las violaciones: "Mi hija mayor fue producto de una violación, a mí me encontraron tirada en un potrero y todo... es muy difícil, eso fue frustrante porque, bueno, la gente lo empieza a mirar a uno como cualquier cosa" (Gladys, 39 años). Sobre ellas se impusieron estigmas, fueron "manchadas", juzgadas por sus familias y consideradas indignas de pertenecer a la comunidad: "Luego de eso todo el pueblo me señalaba y decían que tenía que irme, yo iba a la calle a comprar leche o carne y nadie me la vendía" (Solteny, 48 años). La culpabilización de esas víctimas llegó al punto de sus vecinos negarles el acceso a alimentos y pedirles el abandono de las localidades. Las consecuencias físicas y psicológicas son devastadoras; emocionalmente, sus vidas fueron desbaratadas por la escasa esperanza hacia el futuro, la desconfianza en el otro, la falta de confianza personal, la vergüenza y las representaciones distorsionadas del yo (Manero \& Villamil 2007). ${ }^{4}$ 


\section{Asesinatos de familiares y vecinos}

La victimización indirecta representada por los impactos materiales, simbólicos y psicológicos de los asesinatos de familiares y personas allegadas rompió vínculos afectivos y lazos sociales, traumatizó y dejó a las sobrevivientes solas frente a diferentes demandas y responsabilidades. Tales actos dirigidos contra otros significativos o más allegados afectaron de modo inmediato y mediato a estas mujeres: "Ahí llegaron los paramilitares a Potosí, ahí murieron muchos amigos en esa incursión...yo no podía dormir de sólo pensar que iba a haber otra incursión, yo me acuerdo, que dormía con botas y ropa por si había que salir corriendo" (María Eugenia, 47 años). El asesinato de sus amigos desestabilizó a esta mujer que a partir de ahí pasó a temer por su propia vida presentando, además, disturbios de sueño e hipervigilancia. La mayor tristeza para estas mujeres es perder miembros cercanos que brindaban apoyo material, apoyo social o un sentido de vida compartido. La violencia contra los otros más cercanos transforma lo cotidiano en riesgoso.

Los asesinatos de familiares y vecinos fueron una amenaza para estas mujeres que se vieron en estado de vulnerabilidad. Es aquí donde entra en juego el nivel de capital social y cultural como factor de vulnerabilidad (Almeida \& Paes-Machado 2013), por el temor a perder los lazos construidos en el tiempo: "Siempre es duro, porque uno queda como traumatizado, el conflicto, los problemas, saber que uno tiene familia allá, saber que las personas con las que uno estudió, se crio, están todos muertos por ese mismo conflicto, siempre es muy triste...se va quedando uno como solo" (María Dolores, 34 años). La violencia acabó con los individuos significativos, que representaban un capital social para ellas y la comunidad; muchos eran líderes comunitarios, profesores, sacerdotes, personas destacadas. En otras palabras, aquellos que siempre estuvieron en el pueblo, que influenciaban la opinión pública local, se oponían o podían contrarrestar la pretensión de los señores de la guerra en el monopolio del poder. Tales pérdidas rompieron los lazos de cooperación, desestabilizaron el soporte simbólico y debilitaron los mecanismos para mitigar choques violentos (Jaimes 2008). En este sentido, las mujeres que perdieron sus redes sociales quedaron desamparadas para hacer frente a nuevas situaciones como las que se presentan en las ciudades hacia donde ellas se desplazan: "Eso allá en el pueblo uno hacía de todo, que mataba la gallina, que los tamales, con los vecinos y así, gente conocida... uno bailaba y tomaba, pero ya las cosas cambian por acá [en Bogotá], ya la gente es como envidiosa" (Yomara, 40 años). Es el colapso del ser y estar en el mundo, la desestructuración de las prácticas cotidianas, tanto en la 
esfera pública como privada, así como el tejido social y los vínculos que le dan significado (Ruta Pacífica de las Mujeres 2013).Por otro lado, las atrocidades asociadas a los asesinatos individuales y colectivos, bajo la forma de masacres $^{5}$, confrontaron a las mujeres con situaciones extremas y quedaron en la memoria de forma permanente por su incidencia:

Allá había mucha guerrilla, habían hartos combates, perseguían a la gente, a mi tío, me acuerdo mucho, que nos lo entregaron en una bolsa picado, eso habían muchas muertes por allá.... tengo depresión, soy depresiva, no me dan ganas de salir, no quiero hacer nada, quiero desaparecer, no puedo olvidar varias cosas que pasaron con mi familia y eso me pone triste (Floralba, 33 años).

Las muertes violentas fueron acompañadas en muchas ocasiones por torturas previas, malos tratos físicos y psicológicos. A esta mujer por ejemplo le entregan su familiar desmembrado para aterrorizarla. El impacto para estas mujeres no está ligado solo a la perdida sino al horror asociado a las circunstancias y al modus operandi en las que se produce. De ahí que la única verdad para muchas de esas sobrevivientes es la que está asociada al hecho violento; es decir, para ellas la realidad única es la que se relaciona con el trauma:

Eso de que lleguen y te saquen de tu casa, que veas cómo matan a tus familiares delante de ti y que no puedas hacer nada, que no los puedas enterrar como Dios manda, que de pronto se queden por ahí para que se los coman los gallinazos...es difícil, porque te acuestas en la cama y no puedes dormir, sientes que te corretean, que te persiguen, te levantas gritando, todas esas cosas son difíciles...uno trata de olvidar pero el pasado vuelve, cuando pasó todo eso. Empiezo a imaginar cuando se veía la sangre, a los que tenían amarrados para matarlos...siempre digo que es muy duro... ¿Qué haría usted si viera a sus padres amarrados para matarlos?... Entonces ver que entre los muertos están tus familiares duele mucho, y sin poder hacer nada... entonces es difícil, pase lo que pase eso es difícil de olvidar, eso ya está ahí, aunque quieras olvidar, ya es estable, es parte de tu vida" (María Dolores, 34 años).

En este caso se da una modalidad de asesinato como acto público, es decir, matar a las personas delante de familiares para aumentar el dolor y dejar un impacto imborrable en las sobrevivientes. Cabe destacar que para muchas mujeres que han pasado por esa situación, lo único cierto es la presencia constante de la muerte, lo cual trae consigo inestabilidad física y emocional. Después de sufrir hechos traumáticos, el miedo a nuevas amenazas y violaciones se cierne sobre la vida de estas mujeres (Ruta 
Pacífica de las Mujeres 2013). Para ellas la cuestión de la memoria y el intento desesperado del olvido tiene que ver con la presencia constante de eso tan insoportable que se arraiga en el cuerpo y la mente; la realidad ya no puede volver a percibirse de la misma forma, ya nada va a funcionar igual, y todo eso asociado a un recuerdo articulado a una memoria (Manero \& Villamil 2007).De esta forma, como el mundo cambió, ellas tuvieron que proyectarse de manera distinta y abrir nuevos caminos para sobrevivir solas y con sus hijos en las zonas de conflicto o en los lugares a donde se desplazaron: "Yo vivía con mi esposo, el campo es maravilloso, tiene uno lo necesario... uno en el campo tiene de todo a la mano, es más fácil sobrevivir, pero cuando se mete la violencia, se le voltea a uno el disco, es como nacer de nuevo, toca empezar de nuevo, a crecer sola" (Maria Dolores, 34 años). En muchas circunstancias, esas mujeres pasaron a ser madres cabeza de familia, viviendo necesidades extremas y cayendo incluso en la indigencia (Meertens 1999).

\section{Desapariciones Forzadas}

La desaparición forzada ${ }^{6}$ de esposos, hermanos, padres genera una victimización indirecta que se manifiesta en la incertidumbre respecto a sus paraderos, obligando a estas mujeres a hacer esfuerzos desesperados para encontrarlos y provocando nuevas victimizaciones.

Tales desapariciones que sustraen a los individuos del amparo de la ley privan de la libertad e incluso de la vida a las personas, sin dejar rastro alguno (Agamben 1998; Gómez 2007), estas se realizaban mediante arrestos e invasiones de hogares y fincas. Muchas de ellas acompañadas de tortura para obtener información del enemigo o para intensificar el dolor infligido a la víctima. También se procedía al ocultamiento de los cuerpos mediante incineración o enterramiento en fosas comunes. Fue una práctica muy extendida arrojar cadáveres a los ríos luego de la desaparición (Centro de Memoria Histórica 2013).

Consecuentemente, esos hechos generaron incertidumbre respecto al paradero de la víctima directa, ya que se podían confundir con secuestros u homicidios y estas mujeres quedaban con la incógnita sobre la posibilidad real de siquiera demostrar que la persona estuviese realmente desaparecida: "Yo vengo de San Pablo, Bolívar, allá me desaparecieron al papá de mi hijo y hasta el presente no sé nada, se lo llevaron tres hombres armados, no sé bien, no sé más nada, no ha aparecido, ya debe... eso, ya debe estar muerto" (Adelaida, 37 años). Se trata de una tortura psicológica para la familia y, en 
la mayoría de las ocasiones, un sufrimiento prolongado cuyo duelo resulta difícil, cuando no imposible de concluir:

Mi hermano manejaba un carro y unos hombres lo contrataron para llevarlos a una finca. Desde ahí ya no se supo nada de él, el carro no apareció y todos nos decían que lo habían matado. Nosotros fuimos a un abismo donde acostumbraban a tirar los cuerpos, pero no lo encontramos, decían que en el rio, pero tampoco, eso fue terrible, se cansa uno de buscar. Mi mamá se enfermó por eso y pues ahí aumentó nuestro sufrimiento (Marilsa, 52 años)

Si no se encuentra el cuerpo del ser querido, si no se aclaran los hechos, esto se convierte en una pesadilla continua. Estas mujeres se enfrentan a una serie de preguntas sin respuesta. Dichas interrogaciones son el primer obstáculo en la posibilidad de construir un sentido de lo ocurrido (Patiño, Chaves \& Ramos 2013).

Las mujeres cuyo marido o hijo ha desaparecido están siempre en procura de noticias, de saber sobre el paradero, y en la ausencia de información, ellas emprendieron la tarea de buscar a sus seres queridos, lo cual implicó un enorme esfuerzo. En algunos casos, esta situación las llevó a vender el patrimonio para financiar las búsquedas: "Esto es tan difícil que no se lo deseo a nadie, no puedo volver a mi tierra, de donde me echaron, de donde me sacaron... yo vendí todo para buscar a mi marido y ahí me empezaron a amenazar, a perseguirme" (Aida, 43 años).

De hecho, se trató de una empresa difícil y con frecuencia arriesgada, pues los grupos armados las amenazaron cuando sabían que estaban llevando a cabo averiguaciones propias o acudían a las instituciones: "Yo duré buscando a mi esposo tres meses con la defensa civil, con los bomberos... duré tres meses, fui vendiendo todo, saliendo de todo lo que tenía por buscarlo... y por estar haciendo eso, a mí me amenazaron, entonces eso nos causó mucho problema, mucho daño" (Aida, 43 años).

A estas amenazas y persecuciones se debe sumar la victimización secundaria que resulta de realizar gestiones por cuenta propia y sin el apoyo debido de las instituciones, lo que terminó frustrándolas o reduciendo, en muchos casos, sus expectativas de justicia. Tal victimización secundaria y los sentimientos que esta despierta garantizan que la victimización primaria sea sentida por más tiempo (Paes-Machado \& Nascimento 2006):

Para que nos entregaran el cuerpo nos tocó ir a la alcaldía, nadie nos ayudó, ni el ejército, ni nadie... eso se desmoraliza uno, fuimos a la Defensoría del Pueblo, a la Cruz Roja, pidiendo ayuda... movimos cielo y tierra, pero decían que no lo entregaban porque había muerto en combate, cuando él no era guerrillero. 
Nosotros nos fuimos a hablar con los guerrilleros, nos fuimos a la de Dios, solos. Después de que vieron que insistimos, de allá lo sacaron de una fosa común y lo trajeron. Nosotros denunciamos eso ante los de derechos humanos, pero después comenzaron a amenazarnos (Consuelo, 45 años).

Así, se establece un círculo infernal donde una victimización lleva a otras sin que estas mujeres tengan medios de romper con el mismo o tramitar el duelo:

Ya han pasado diez años [de la desaparición], uno se acostumbra a llevarlo como cuando uno tiene una enfermedad... por ejemplo, cuando a uno le matan un familiar; cuando se lo matan, se lo entregaron, ya uno lo llevó al cementerio y ya uno sabe, pero mire usted la incógnita que uno tiene todos los días de esa persona que desaparecieron hace diez años...yo a veces sola me pongo a pensar si lo torturaron, no lo torturaron, żqué le hicieron?, żónde están los restos?, o si está vivo, ¿qué hicieron con él?, o sea, todas esas preguntas yo las tengo ahí como interrogante" (María, 38 años).

Dado que el duelo es una respuesta del sujeto ante la pérdida del objeto y al sentimiento de desintegración física y emocional (Freud 1917), es preciso tramitar la pérdida que acompaña la partida del ser querido (Figueroa 2004). Para remediar ese sentimiento son hechas las ceremonias fúnebres. Pero en el caso de las parientes de los desaparecidos ese trámite no fue posible. De igual manera, las desapariciones también provocaron la desmembración y fragilización de los grupos familiares, llevando a las mujeres a ser madres cabeza de familia. Además, tales pérdidas violentas de seres queridos traen consecuencias específicas como mujer, en su identidad de género, así como de estigmatización, separación familiar y aislamiento social que se relaciona con tener familiares desparecidos (Ruta Pacífica de las Mujeres 2013).

\section{Resistencia contra el reclutamiento forzado}

La resistencia (Scott 1984) de estas mujeres frente al reclutamiento forzado ${ }^{7}$ de sus hijos e hijas se expresa en las estrategias utilizadas para facilitar las deserciones a través de la desobediencia, el planeamiento de huidas, y dado el caso, la invasión de campamentos de los grupos armados para liberar a los reclutados ${ }^{8}$. La motivación de esos actos de resistencia cotidiana proviene del inconformismo y la reacción frente a la amenaza por parte de los actores armados: aquellos que, independientemente de los colores políticos-partidarios e ideológicos, vienen para secuestrar o "robar" a sus 
hijos, causar pérdidas sustanciales (Durston 2002) o desmembrar el grupo familiar. Estas mujeres perciben a sus hijos como el objetivo y la razón de ser y hacer, entran en su mundo como un proyecto de vida y un elemento estructurante de su subjetividad: "A mis hijos les dijeron que los iban a coger para llevárselos, yo no los volví a mandar al trabajo en el campo y los saque del pueblo...porque mis hijos son lo único que tengo, son todo, me hacen sentir bien en los momentos de tristeza, son todo para mí" (Olga Patricia, 42 años). La preocupación con el probable reclutamiento de sus hijos hizo que esta madre no dudara en sacarlos rápidamente de la región.

De ahí que estas mujeres se hayan expuesto a acciones arriesgadas y situaciones peligrosas para salvaguardar o liberar a sus hijos:

Mi hijo estaba llorando, yo le pregunté por qué lloraba y él estaba alistando una maleta con ropa, luego dijo que los iban a reclutar. Cuando me dijo eso le respondí: "No mijo, usted no se va por allá...primero muerta, tendrán que pasar por encima de mi cadáver, pero yo no lo dejo llevar". Yo lo empaqué en un camión y lo mandé para Bucaramanga. Pensé que así iba a pasar todo, pero después me llegó una carta de destierro en donde me decían que tenía 24 horas para salir del pueblo (María Eugenia, 47 años).

Esta mujer también sacó a su hijo de la región para evitar su reclutamiento, pero a diferencia de la madre anterior, fue amenazada por el grupo armado que la obligó a abandonar el pueblo y dejar todo lo que había construido en el tiempo.

En varias ocasiones, las mujeres dieron testimonio de temer más por la vida de los miembros de la familia que por la vida e integridad propia (Ruta Pacífica de las Mujeres 2013):

Cogí un machete y me fui para donde me dijo un sargento. Cuando llegué al lugar, había una casa vieja y una guerrillera estaba cuidando, estaba sola... pues yo cogí un palo y se lo mandé por la cabeza, no sé de donde saqué fuerzas, ni sé cómo abrí la puerta de la casa. Y cuando abro veo a mi muchacho ahí tirado en el suelo con otro poco de muchachas embarazadas, otras estaban como enfermas y flaquitas...me dio mucho pesar y entonces me eché a la más flaquita a la espalda y salí corriendo con mi hijo (Mary, 56 años).

En este caso, la acción fue más arriesgada, pues esta mujer se armó para buscar a su hijo en un campamento guerrillero, llegando a agredir a una miliciana para poder liberarlo. No satisfecha con esto, también liberó a otras jóvenes y en particular a aquella que parecía no tener fuerzas para huir. A partir de ahí sólo le restó la salida de la región para salvar su vida y la de su familia. 
Tal resistencia cotidiana está fundada en una responsabilidad moral respecto al cuidado de la familia. Para ellas existe un lazo bastante profundo con la maternidad y su significado. El ejercer la maternidad supone una responsabilidad en la crianza y el crecimiento para llegar a la vida adulta, el que este proceso sea truncado implica serias consecuencias afectivas. Se podría afirmar también que hay una diferencia sustancial entre el impacto del miedo como mujer y como madre (Ruta Pacífica de las Mujeres 2013). En este sentido, el dolor de una madre es más fuerte y permanente, y claro, tendrá que ver justamente con el vínculo que existe entre madre e hijo, así como el cuidado intensificado del otro y la protección redoblada de la familia en ambientes de conflicto armado (Lindsey 2000; Malakunas 2001). Aunque dicha micro resistencia que se expresa en las estrategias para la deserción de sus hijos haya provocado represalias contra las mujeres, también de alguna manera ha salvado vidas y contribuido para minar una de las bases de la reproducción de dicho conflicto: la participación de los jóvenes en las organizaciones armadas.

\section{Desplazamiento forzado}

El desplazamiento forzado es una consecuencia de ese círculo de factores negativos (Brittain 2003), así como de la lucha por la sobrevivencia y de la resistencia cotidiana frente a los grupos armados ${ }^{9}$. Tal desplazamiento viene asumiendo varias direcciones socio-espaciales: campo-campo, campo-ciudad y pendular.

Los movimientos campo-campo se realizan de manera intempestiva o poco organizada. Se caracterizan por la salida de los lugares de origen hacia las cabeceras de las poblaciones cercanas y se hace bajo la presión de los combates entre grupos armados o las incursiones sorpresivas de estos en las poblaciones. Estas salidas por lo general se hacen con varios grupos familiares:

Eso fue muy rápido, yo escuchaba tiros y gritos, eso fueron pocos minutos para salir y tuvimos que coger trochas [camino en la selva o el monte] con mucha gente, fueron varios días de camino, eso fue difícil porque no sabíamos nada de las otras personas, de la familia... fue muy duro porque salimos con lo que teníamos encima...dejamos todo y sin saber para dónde ir ¿Qué va a pasar contigo?, ¿Con los hijos? Fue muy difícil. Salimos muchas familias de Salaquí, Chocó y llegamos a Rio Sucio donde ya era el pueblito (María Dolores, 34 años).

Se trata de una huida para salvar la vida, sin destino definido, pero que por lo general llevó a estas familias a hacer desplazamientos cortos para 
poblaciones cercanas dentro de las mismas regiones. En este tipo de salida aún se conserva la esperanza de retornar a sus hogares y fincas luego de que pase el peligro. Sin embargo, cuando sufren nuevas victimizaciones, no encuentran medios de vida o pierden la perspectiva de quedarse, estas mujeres planean salidas definitivas y más organizadas.

El desplazamiento campo-ciudad se hace de forma dispersa y planeada, obedeciendo a las circunstancias propias del ambiente de zozobra y terror instaurado por los grupos armados. Se responde al estrés y la angustia constante, a las amenazas de reclutamiento, las extorsiones o persecuciones. Hubo un tiempo mínimo para tomar la decisión y organizar algunas estrategias de huida, es un tipo de movimiento preventivo y en algunos casos silencioso ya que implica sólo un núcleo familiar o madres jefas de hogar con sus hijos. Estas migraciones se hicieron hacia ciudades más grandes y en busca de redes de apoyo más estables:

A mí me dijeron que si no pagaba la cuota [extorsión], en ocho días se llevaban a mi hija. Siempre tenía miedo y pues yo no iba a pagar nada. Ahí comenzaron las amenazas y decidí salir del pueblo, me fui con pocas cosas, lo que podía sacar de noche. Después le decía a mis familiares que me mandaran el resto de mis cosas en un camión, así fui sacando lo que pude (Carmen, 38 años).

En una acción que también se inscribe en la resistencia cotidiana (Scott 1984), esta mujer huyó del pueblo para librarse de la extorsión y de la amenaza de secuestro que pesaba en contra de su hija. Para facilitar la huida y el establecimiento en los lugares de destino, algunas mujeres recurrieron a lazos y redes sociales en las ciudades.

Otras mujeres efectuaron desplazamientos pendulares (Baños 2001) entre los lugares de origen y de destino. Aquí hablamos de una primera salida para protegerse y huir del peligro, luego el retorno al lugar de origen con la esperanza de recuperar lo que se abandonó seguido por una nueva salida para la ciudad:

El primer desplazamiento fue porque mataron a mi suegro, a él lo amarraron, lo torturaron... y bueno, de ahí salimos todos con mi marido para Chaparral. Ahí pasamos unos días y luego nos devolvimos para la finca, pero allá luego la delincuencia común [paramilitares] comenzaron a molestarlo porque él empezó a colaborar como miliciano de la guerrilla. De ahí pues, decidimos volver a salir para Ibagué, pero seguían las amenazas, ahí pues yo dije que me venía para Bogotá, pero él no quiso salir conmigo, entonces me vine con mi suegra y los niños (Nilba, 49 años). 
La participación en la guerrilla, la muerte del suegro y después las amenazas al marido que continuó involucrado como miliciano, provocan un movimiento de ida y vuelta de la familia, generando sentimientos de frustración e inestabilidad al no poder establecerse en un lugar fijo (Baños 2001). Aquí vemos que la salida se hizo con el grupo familiar: madre, esposo e hijos, incluso parientes cercanos. Sin embargo, llega un punto en que la desintegración familiar es inminente por diferentes motivos. A veces, por más que las mujeres quieran conservar los vínculos familiares, el desplazamiento inevitablemente produce el distanciamiento físico de los integrantes de la familia, entre otras cosas por la dificultad que tienen algunos de los miembros para asimilar la salida (Lindsey 2000). Así, se vieron sobrecargadas con más tareas como el cuidado de los hijos, la protección de la familia, el sustento económico en el viaje, la búsqueda de ayuda, entre otros esfuerzos realizados durante el éxodo.

Aunque el desplazamiento es interno, es decir, dentro del mismo país y las víctimas son colombianas, la llegada a los lugares de destino implica nuevas tensiones y conflictos. Para estas mujeres es difícil ejercer sus derechos, su condición de víctimas y desplazadas las coloca en un estado provisional, de no ciudadanía (Agamben 1998), lo que hace que sean ignoradas y excluidas en sus nuevos contextos de vida. De cualquier forma, el desarraigo forzado afectó a estas mujeres no solo en la satisfacción de sus necesidades básicas y la pérdida de estatus, sino que además sufrieron empobrecimiento y reducción en su participación social (El Bushra \& Piza 1993). Es el tiempo de rupturas y también de reconstrucciones.

\section{Conclusiones}

En este trabajo que analiza los efectos del conflicto armado colombiano sobre las mujeres, buscamos una comprensión específica de tales efectos y al mismo tiempo más próxima a la experiencia de los sujetos. En ese sentido, el conflicto bélico que se desarrolla en varias regiones del país debe ser visto como un proceso social de estructuración (Giddens 1984; Walkate 2003), promoción y materialización de oportunidades de victimización efectiva y potencial, recurrente y masiva de sectores de la población civil, como las mujeres, que han estado en posición de desventaja frente a los hombres (Osorio 2008; Cockburn 2005; Cifuentes 2009). Dado que el género se constituye como el campo donde adquieren significado las relaciones de poder basadas en la diferencia de los sexos, la guerra aumenta esa asimetría a través de la multiplicación de riesgos e imposición de daños. 
Considerando la interpenetración y la dificultad de separar los daños, definimos algunos tipos y subtipos de victimización que afectaron a estas mujeres como las pérdidas materiales, la violencia sexual y las pérdidas físicas efectivas y potenciales de sus otros significativos o más allegados. En ese sentido, a pesar de la violencia sexual aquí abordada parecer ser la forma específica de victimización, la mirada atenta sobre los daños compartidos con otros grupos de la población civil - pérdidas materiales, asesinatos y desapariciones - reveló especificidades no menos graves para las mujeres.

Aun con respecto a la violencia sexual, se observó que los grupos armados abusaron del cuerpo femenino para mostrar poder, instaurar miedo y desmoralizar a las víctimas (Osorio 2008; Manero \& Villamil 2007). Estos abusos fueron facilitados por la cotidianización y normalización de la violencia, por el estado de vulnerabilidad resultante de las invasiones de los hogares y fincas, así como en algunos casos, por la ausencia de los hombres. De igual manera, las mujeres sufrieron violencia sexual por desobedecer órdenes de los grupos armados, participar en organizaciones percibidas como enemigas (Ruta Pacífica de las Mujeres 2013; Osorio 2008) o tener relaciones afectivas con miembros del bando contrario. Además de las consecuencias físicas y psicológicas devastadoras, esta violencia afectó negativamente los lazos familiares y comunitarios de las víctimas.

La victimización material, provocada por la destrucción, la ocupación y la apropiación de los bienes, la explotación de la fuerza laboral y la pérdida de puestos de trabajo minó y destruyó las condiciones de reproducción social de mujeres de zonas rurales y urbanas en las regiones de conflicto. Asociado a esas acciones, a estas mujeres les fueron asignados trabajos civiles o militares ligados al conflicto armado que, en muchos casos, asumían un carácter de explotación y esclavización. Ellas tuvieron que trabajar en dobles jornadas, por un lado, asistiendo a sus familias y por el otro, colaborando en las tareas que exigían los grupos armados (Stasiulis 1999). De manera general, las pérdidas materiales que fueron más brutales para las mujeres campesinas, provocaron declive social, nostalgia por el objeto perdido (Uriarte 1998; Ruta Pacífica de las Mujeres 2013) y sentimientos de incertidumbre. Además, esas pérdidas materiales hacen más costosa la adaptación e intensifican la pobreza en los lugares de destino hacia donde ellas se desplazaron.

A su vez, la victimización indirecta representada por los impactos materiales, simbólicos y psicológicos de la victimización directa de familiares y personas allegadas confrontó a estas mujeres con situaciones extremas. Tanto los asesinatos como las desapariciones de esos otros significativos transforman lo cotidiano en riesgoso, rompiendo vínculos afectivos e identitarios profundos, traumatizando y dejando a las mujeres solas ante diferentes 
demandas y responsabilidades familiares. En cuanto a las desapariciones, estas sembraron terribles incertidumbres respecto al paradero de los seres queridos, obligándolas a hacer esfuerzos desesperados para encontrarlos. A su vez, esas búsquedas provocaron empobrecimiento y llevaron a nuevas victimizaciones de las sobrevivientes sea por parte de las organizaciones armadas, sea por parte de las instituciones gubernamentales y no gubernamentales.

Tales eventos vivenciados o divulgados aproximaron de manera dramática la perspectiva de pérdida de los hijos y agudizaron la aprehensión frente al reclutamiento de ellos por parte de los grupos armados. De ahí que ellas se hayan expuesto a acciones arriesgadas y situaciones peligrosas para salvaguardar o liberar a sus hijos de tal reclutamiento. Se podría afirmar que hay una diferencia sustancial entre el impacto del miedo como mujer y como madre (Ruta Pacífica de las Mujeres 2013). El dolor de una madre es más fuerte y permanente por el vínculo existente entre madre e hijo en el proceso de crianza. Aunque dicha resistencia al reclutamiento, que se expresó en estrategias de deserción de sus hijos, haya provocado represalias contra las mujeres y no haya influido en la espiral del conflicto armado, también ha salvado vidas y contribuido a minar una de las bases de la reproducción de dicho conflicto: la participación de los jóvenes en las organizaciones armadas. Finalmente, el desplazamiento forzado puede ser visto como una síntesis de todas esas determinaciones: la victimización, la lucha por la sobrevivencia y los actos de resistencia cotidiana. Se trata de una huida que las alejó de los escenarios de conflicto y los riesgos extremos, proporcionando un alivio inmediato para el dolor de la guerra (Nin 2005). Sin embargo, los efectos asociados al desplazamiento garantizan que el peso de las victimizaciones sea sentido por más tiempo. Sus efectos siguen acompañándolas y proyectándose en sus nuevos modos de vida en los lugares de destino. Aquí, los impactos para ellas y sus hijos aún precisan ser conocidos.

Recebido em: 02/04/2018

Aprovado em: 29/01/2019

Edwin Diego Salcedo Ávila

Psicólogo de la Universidad Nacional de Colombia y Magister en Ciencias Sociales de la Universidad Federal de Bahía, Brasil. Trabaja e investiga temas relacionados con conflictos armados y refugiados.

Eduardo Paes-Machado

Sociólogo y criminólogo; profesor titular de sociología de la Universidad Federal de Bahía, Brasil. Investiga temas relacionados con victimización, seguridad y mercado de drogas. 


\section{Notas}

1 La carrera de víctima de estas mujeres también implicó gastos imprevistos como: pagos a abogados, servicios funerarios para enterrar a sus familiares o buscar a parientes desaparecidos, gastos médicos e inversión en pasajes para la salida de sus lugares de origen.

2 En el conflicto armado colombiano se ha practicado la violencia basada en género (VBG), violencia sexual o de otro tipo, que se apoya en las normas y exclusiones de género para desmoralizar física y psicológicamente a las personas (El Jack, 2002). Aunque hombres y mujeres hayan sido víctimas y objeto de violación, los blancos de la VBG son más a menudo las mujeres. Estos actos no están relacionados con el placer sexual, y si con el poder que se ejerce sobre la víctima. Aquí el cuerpo se reclama en tanto objeto, susceptible de ser controlado, de ser apropiado por parte del violador para colonizarlo (Brownmiller 1975).

3 De igual manera se extendió la práctica por parte de los grupos paramilitares de reclutar menores de edad para esclavitud sexual. Estas mujeres fueron obligadas a tener relaciones sexuales con miembros del grupo y sobretodo con comandantes

4 Además la violencia sexual reduce a las víctimas, obligándolas a callar y eso hace más difícil su situación: "Yo era muy bonita, creo que por eso me tenían como ganas...ahí fue cuando pasó todo...no, eso es duro...no, mejor no hablo de eso" (Ana, 45 años). La imposibilidad de hablar también se asocia al estigma, al miedo o la vergüenza: "siempre estoy triste, me acuerdo y me da rabia...que quiere que le diga, no sé...me tocó hacer cosas feas...pero mejor no hablemos, pregunte otra cosa ¿̇ué quiere saber? (María, 27 años). Para esta mujer hablar genera malestar y disgusto en la medida que eso significa descubrir realidades que pertenece a la intimidad, al propio cuerpo violado.

5 Los asesinatos sobre todo los practicados por los grupos paramilitares asumían la forma de masacres para darles visibilidad, exhibir crueldad y generar terror. Las masacres buscaban también la devastación en la modalidad de tierra arrasada (Centro de Memoria Histórica 2013) en donde se destruyeron bienes materiales, se violentaron a las mujeres y se escenificaban actos de tortura, humillación y vejaciones contra niños o ancianos.

6 El fin de este acto delictivo es buscar información, generar miedo en los familiares del desaparecido, preservar la impunidad y eliminar personas (Centro de Memoria Histórica, 2013).

7 Dicho reclutamiento ocurre muchas veces mediante la manipulación psicológica, ofreciendo beneficios o mostrando una visión positiva del reclutamiento ajena a la realidad (Ruta Pacífica de las Mujeres, 2013). 
8 Además de esas modalidades de resistencia, hay familias que negocian y pagan extorsiones a las organizaciones armadas para que estas no recluten a sus hijos.

9 Ese proceso abarcó los eventos y hechos previos al éxodo, la salida, los tiempos y las rutas migratorias, la llegada a un lugar nuevo y las diversas estrategias de reconstrucción de las vidas y de sobrevivencia en los lugares de destino (Riaño, 2006; Naranjo, 2001). 


\section{Referências bibliográficas}

ACNUR (Agencia de la ONU para los Refugiados). 2017. "Situación Colombia". UNHCR ACNUR Colombia. Disponible en: http://www.acnur.org/ donde-trabaja/america/colombia/

AGAMBEN, Giorgio. 1998. Estado de excepción. Buenos Aires: Adriana Hidalgo Editora.

ALMEIDA, Odilza Lines \& PAES-MACHADO, Eduardo. 2013. "Processos sociais de vitimização prisional". Tempo Social, 25(1): 257-286.

BAÑOS, Othón. 2001. La modernidad rural mexicana a fines de milenio. El caso de Yucatán. Mérida: Universidad Autónoma de Yucatán.

BENNETT, Olivia, BEXLEY, Jo \& WARNOCK, Kitty. 1995. 'Introduction'. In: O. Bennett, J. Bexley \& K. Warnock (org), Arms to Fight, Arms to Protect: Women Speak Out About Conflict, London: Panos Publications. pp 2-12.

BIERNACKI, Patrick \& WALDORF, Dan. 1981. "Snowball sampling: problems and techniques of chain Referral Sampling". Sociological Methods and Research, 10(2): 141-163.

BOURDIEU, Pierre \& ABDELMALEK Sayad.1964. Le Derácinement, la crise de l'agriculture traditionnelle en Algérie. Paris: Minuit.

BRITTAIN, Victoria. 2003. "The impact of war on women". Race \& Class, Vol. 44(4): 41-51.

BRODEUR, Jean-Paul. 2004. "Por uma sociologia da força pública: considerações sobre a força policial e militar". CADERNO CRH, Salvador, 17 (42): 481-489.

BROWNMILLER, Susan. 1975. Against our will. Men, Women and Rape, New York: Pelican Books.

CARBÓ, Eduardo. 2006. La nación soñada. Violencia, liberalismo y democracia en Colombia. Bogotá: Grupo Editorial Norma.

CARRIÇO, Raquel \& MATTOS, Matheus. 2012. "Teoria fundamentada em dados. Uma experiência metodológica". Revista Latinoamericana de Metodología de la Investigación Social. n 3 abril-septiembre.

CENTRO DE MEMORIA HISTORICA. 2018. "Observatorio de Memoria y Conflicto del CNMH" Centro Nacional de Memoria Histórica. Disponible en: http://centrodememoriahistorica. gov.co/observatorio/

2013. iBasta ya! Colombia: memorias de guerra y dignidad. Informe General Grupo de Memoria Histórica. Bogotá: Imprenta Nacional.

CIFUENTES, María R. 2009. "La investigación sobre género y conflicto armado". Revista Eleuthera. v 3, enero-diciembre: 127-164.

CHARMAZ, Kathy. 2006. Constructing grounded theory. A practical guide through qualitative analysis . London: Sage.

COCKBURN, Cynthia. 2005. Género, conflicto armado y violencia política. Washington D.C: Banco Mundial.

DURSTON, John. 2002. El capital social campesino en la gestión del desarrollo rural. Washington: United Nations Publications.

EL BUSHRA, Judy \& PIZA, Eugenia. 1993. Development in Conflict: The Gender Dimension. UK and Ireland: Oxfam.

EL JACK, Amani. 2002. Género y conflictos armados, Informe general. UK: Institute of Development Studies.

ENLOE, Cynthia. 1995. Para desmilitarizar la sociedad. Mujeres en acción. Paris: Isis Internacional.

ESTRADA, Angela M, IBARRA, Carolina \& SARMIENTO, Estefania. 2007. 
"Regulation and control of subjectivity and private life in the context of armed conflict in Colombia". Community, Work and Family Vol. 10, No. 3, August: 257-281.

FIGUEROA, Mario. 2004. "El duelo en el duelo. La persecución y la venganza". Revista Desde el Jardín de Freud, n 4: 34-55

FREUD, Sigmund.1917. Duelo y melancolía. Buenos Aires: Obras Completas Amorrortu Editores.

GIDDENS, Anthony. 1984. The constitution of society. Cambridge: Polity Press.

GÓMEZ, Juan J. 2007. “La desaparición forzada de personas. Avances en el Derecho Internacional". Revista Mexicana de Política Exterior, n 76: 27-49.

GRINNELL, Richard \& UNROU, Yvonne. 2007. Social Work Research and Evaluation. Quantitative and Qualitative Approaches. Oxford: University Press.

HERNANDEZ, Roberto. 2010. Metodología de la Investigación. México: McGraw Hill.

JAIMES, Nora. 2008. "Efectos directos del conflicto armado en el Catatumbo. Desplazamiento, pérdida de capital humano y alteración en el mercado laboral". Revista del ICEE, Año VI, n 10 Enero-Diciembre: 129-146.

KURTENBACH, Sabine. 2005. Análisis del Conflicto en Colombia. Bogotá: Editorial Gente Nueva.

LIRA, Elizabeth.1991. "Psicología de la amenaza política y el miedo" Grupo de Acción Comunitaria. Centro de recursos en Salud Mental y Derechos Humanos. Disponible en: http://www.psicosocial.net/grupo-accion-comunitaria/centro-de-documentacion-gac/fundamentos-y-teoria-de-una-psicologia-liberadora/ psicologia-y-violencia-politica/134-psicologia-de-la-amenaza-politica-y-el-miedo/file
LINDSEY, Charlotte. 2000. "Las mujeres y la guerra". Revista Internacional de la Cruz Roja. Disponible en: https:// www.icrc.org/spa/resources/documents/misc/5tdp9q.htm\#3

MALAKUNAS, Karl. 2001. "U.S. Cluster Bomb Attack Kills Nine, Empties Village" UN Agence France Presse, 25 de octubre.

MANERO, Roberto \& VILLAMIL, Raul. 2007. "Notas sobre violencia, tortura, terrorismo de Estado y erotismo". El Cotidiano, v 22, n 143, mayo-junio: 18-25.

MEDINA, Fernando. 2009. "El Conflicto armado en Colombia: nuevas tendencias, viejos sufrimientos". Misión Jurídica. Revista de Derecho y Ciencias Sociales, n 2, enero-diciembre: 161-177.

MEERTENS, Donny. 2006. Ensayos sobre tierra, violencia y género. Hombres y mujeres en la historia rural de Colombia (1930-1990). Bogotá: Universidad Nacional de Colombia. CES.

MERTEENS, Donny. 1999. "Género, desplazamiento, derechos" Aprende en línea. Plataforma Académica Universidad de Antioquia. Disponible en: http://aprendeenlinea.udea. edu.co/lms/moodle/mod/page/view. php?id = 26627

NARANJO, Gloria. 2001. "El desplazamiento forzado en Colombia. Reinvención de la identidad e implicaciones en las culturas locales y nacional". Scripta Nova. Revista Electrónica de Geografía y Ciencias Sociales. Universidad de Barcelona. Disponible en: http://www.ub.edu/ geocrit/sn-94-37.htm,

NIN, Bao. 2005. El dolor de la guerra. B. Barcelona/Buenos Aires: S.A. Ediciones.

OOSTERHOFF, Pauline, MILLS, Elizabeth \& OOSTEROM, Marjoke.2014. “Addressing Sexual Violence in and 
beyond the 'Warzone'" Institute of development studies. Vol. 07 June: 1-5. OSORIO, Flor E. 2008. " Forced Displacement among Rural Women in Colombia". Latin American Perspectives, Issue 163, Vol. 35 No. 6, November: 29-40.

PAES-MACHADO, Eduardo \& NASCIMENTO, Ana Márcia. 2006. “Bank money shields: work-related victimisation, moral dilemmas and crisis in the bank profession". International Review of Victimology, 13 (1), 1-25.

PATIÑO, Rafael A, CHAVES, Antonio \& RAMOS, Francisco. 2013. "Significações da condição de vítima entre familiares de desaparecidos forçados no conflito armado colombiano". Revista Colombiana de Ciencias Sociales, n 4, julio-diciembre: 223-243.

PINO, Ana C. 2004. “Expresiones del patriarcado en la sociedad colombiana y sus manifestaciones en el conflicto armado". LA RED VA. Internacional Feminista. Disponible en: http:// www.fire.or.cr/marzo02/repem.htm,

PRADA, Diego O. 2016. Los gastos de la guerra en Colombia 1964-2016: 179 millones de dólares perdidos. Bogotá: Uniciencia/Indepaz.

RANGEL, Alfredo. 1998. Colombia: guerra en el fin de siglo. Bogotá: Ediciones Uniandes.

RIAÑO, Pilar. 2006. “El desplazamiento interno y los trabajos de memoria. Los talleres de memoria". In: M. Bello (org), Investigación y desplazamiento forzado. Bogotá. Colciencias: pp. 1-19.

RUTA PACIFICA DE LAS MUJERES. 2013. La verdad sobre las mujeres víctimas del conflicto armado colombiano. Bogotá: RPM.

SALCEDO, Diego. 2015. Mujeres y conflicto armado: estudio sobre victimi- zación de mujeres desplazadas por la violencia colectiva en Colombia. Dissertação de Mestrado, Universidade Federal da Bahia.

SÁNCHEZ, Olga A. 2008. Las violencias contra las mujeres en una sociedad en guerra. Bogotá: Ruta Pacífica de las Mujeres.

SCOTT, James C. 1984. Everyday forms of peasant resistance. New Haven: Yale University Press.

STASIULIS, Daiva. 1999. "Relational Positionalities of Nationalisms, Racisms, and Feminisms". In: C. Kaplan; N. Alarcon; M. Moallem (orgs), Between Woman and $\mathrm{Na}$ tion: Nationalisms, Transnational Feminisms and the State. Durham and London. Duke University Press.

THEIDON, Kimberly. 2006. "Género en transición: sentido común, mujeres y guerra". Análisis Político, n 60, mayo-agosto: 3-30.

UNIDAD DE VICTIMAS 2018. “En Colombia: 4.2 millones de víctimas del conflicto armado son mujeres" Unidad de Víctimas. Disponible en: https://www.unidadvictimas.gov.co/ es/enfoques-diferenciales/en-colombia-42-millones-de-victimas-delconflicto-armado-son-mujeres-alan

URIARTE, Clara.1998. "Depresiones narcisistas en las neurosis". Revista Uruguaya de Psicoanálisis. Disponible en: http://www.apuruguay.org/apurevista/1990/1688724719988804.pdf

WALDMAN, Peter.1997. "Cotidianización de la violencia: el ejemplo de Colombia". Análisis Político, No 32: 33-51.

WALKLATE, Sandra.2003. Understanding criminology: current theoretical debates. Buckinghan/Philadelphia: Open University Press. 


\section{VICTIMIZACIÓN Y DESPLAZAMIENTO FORZADO DE MUJERES EN EL CONFLICTO ARMADO COLOMBIANO}

\section{Resumen}

Este trabajo discute la victimización de mujeres en el conflicto armado colombiano utilizando datos de entrevistas con mujeres desplazadas de las zonas de conflicto y analizando la victimización por pérdidas materiales, violencia sexual, asesinatos y desaparición de personas más allegadas. Esta investigación muestra que a pesar de la violencia sexual ser la forma más específica de victimización de las mujeres, las demás victimizaciones también tuvieron una fuerte incidencia sobre ellas. Mientras la destrucción del patrimonio material minó la reproducción social de sus grupos familiares, las pérdidas efectivas y potenciales de personas significativas afectaron los lazos de maternidad, cuidado y protección por parte de ellas. Concluye que la sobrecarga de ahí resultante obligó a estas mujeres a reaccionar frente a los grupos armados y huir de sus lugares de origen para proteger sus familias.

Palabras clave: Colombia, Conflicto armado, Mujeres, Victimización, Resistencia, Desplazamiento forzado

\section{VICTIMIZATION AND FORCED DISPLACEMENT OF WOMEN IN COLOMBIA'S ARMED CONFLICT}

\section{Abstract}

This paper discuses victimization of women in Colombia's armed conflict. It uses data from interviews with women who were displaced from the conflict zones. It analyzes victimization from material losses, sexual violence, and murder and disappearance of loved ones. It demonstrates that, although sexual violence is the most specific form of victimization faced by women, the other forms of victimization also had a strong impact on them. While the destruction of material patrimony undermined the social reproduction of their family groups, the effective and potential loss of loved ones affected those women's ties of maternity, care, and protection. The paper concludes that the resulting burden forced those women to react to the armed groups and flee from their places of origin to protect their families. Keywords: Colombia, Armed conflict, Women, Victimization, Resistance, Forced displacement 


\section{VITIMIZAÇÃO E DESLOCAMENTO \\ FORÇADO DE MULHERES NO \\ CONFLITO ARMADO COLOMBIANO}

\section{Resumo}

Este trabalho discute a vitimização de mulheres no conflito armado colombiano utilizando dados de entrevistas com mulheres deslocadas das zonas de conflito e analisando a vitimização por perdas materiais, violência sexual, assassinatos e desaparecimento de pessoas mais próximas. Esta investigação mostra que, apesar de a violência sexual ser a forma mais específica de vitimização das mulheres, as demais vitimizações também tiveram uma forte influência sobre elas. Enquanto a destruição do patrimônio material minou a reprodução social dos seus grupos familiares, as perdas humanas efetivas e potenciais de pessoas significativas afetaram os laços de maternidade, cuidado e proteção por parte delas. Conclui-se que a sobrecarga daí resultante obrigou essas mulheres a reagirem contra os grupos armados e a fugirem dos seus lugares de origem para proteger suas famílias.

Palavras-chave: Colômbia, Conflito armado, Mulheres, Vitimização, Resistência, Deslocamento forçado. 